\title{
The nutritional implications of changing food systems in Eastern Europe
}

\author{
BY BRUCE TRAILL ${ }^{1,2}$ AND SPENCER HENSON ${ }^{1}$ \\ Departments of ${ }^{1}$ Agricultural Economics and Management and ${ }^{2}$ Food Science and Technology, \\ University of Reading, Reading, Berks RG6 $2 A J$
}

\section{INTRODUCTION}

Since the political changes within Eastern Europe in 1989 a process of radical economic reform has been initiated. These reforms will involve a total restructuring of the food production system in these countries and changes in the food choices available to consumers. The aim of the present paper is to assess the implications of these changes particularly regarding the consequences for food consumption patterns.

\section{THE NATURE OF MARKET AND COMMAND ECONOMIES}

As economists interested in food consumption and its consequences for nutrition, a major concern is the mechanism by which decisions are made about the production and consumption of food products. A number of key problems have to be solved in the allocation of resources to the production of food products: (1) what to produce, (2) how to produce it, and (3) who to produce it for. A continuum of economic decision-making mechanisms exists with capitalism and command economies at the extremes. Each adopts markedly different objectives and mechanisms in achieving these objectives with important consequences for the food system.

In a market economy the signal used to allocate resources to the production of food is the price mechanism. The interaction of consumers and producers in the market-place results in a price which equates the quantity producers are able and willing to supply with the amount consumers are able and willing to purchase. Production decisions are made by producers who aim to maximize their financial returns (profits) and who have little regard for the consequences of their actions, for example, on the nutrition of the general population. The distribution of food within the population is not according to need but on the basis of effective demand. That is, consumers with the most money have the greatest demand for food products and so have the greatest say in what is produced. The aim of the system is to maximize efficiency with little regard for equity.

In a command economy decisions as to what is produced are taken by the political system. Decisions are, therefore, made according to an explicit assessment of what an economy can and should produce and on declared political objectives. Price is not the key tool for resource distribution but is generally controlled as part of overall political objectives. In the case of food, prices are typically maintained at low levels which do not reflect the true costs of production. The result is the absence of a natural mechanism by which demand and supply are equated and no linkage exists between what consumers would wish to buy and what is actually available in terms of quantity and quality of food products.

No examples exist of pure capitalist or command systems, all economies have features of both. However, different countries are placed at different stages along the continuum between the two economic systems. The countries of Eastern Europe were traditionally 
close to the command end of the spectrum, whilst much of the rest of Europe was towards the other end of the scale. However, since the drive towards economic reform, the former countries have started to move away from the command, and towards the capitalist system of resource allocation. The major implication of this is the increased role of price as an indicator of consumer demands. This requires the removal of price controls and the formation of a properly functioning market resulting in increases in the cost of food particularly where prices were previously held at low levels.

The reform of the economies of Eastern Europe involves a reduction in the role of the government in the control of the economy. However, it is uncertain how far these countries will proceed down the track towards free markets, but no country in the world employs a perfectly free market system. The market mechanism is prone to a number of failures which are unacceptable in modern societies. At the extreme, if a consumer has no money under pure capitalism, they will starve. Hence, governments intervene with welfare programmes, social security, food stamps etc. where equity considerations are important. Free markets allow consumers to adopt any eating patterns they desire, although the provision of information to guide consumers in such decisions may be imperfect. Governments may intervene to regulate, label and otherwise control the sale of foods considered unsafe for the good of individual consumers and society in general. The government may also intervene in the production-side to ensure security of supply and fair returns to producers. This is particularly the case in the food sector where agricultural policy represents a major government intervention. Therefore, governments always have a role in economic management, the question is the degree to which intervention is acceptable.

\section{FACTORS INFLUENCING FOOD CONSUMPTION PATTERNS}

Whatever shade of economic system is in force, a common set of factors will influence the pattern of food consumption within a country as a whole and within specific population subgroups. Both sides of the market are important as can be seen by considering the structure of the food chain (Fig. 1). The demand-side, which represents the interface between consumers and the rest of the food chain, determines which foods consumers wish and are able to consume. Important factors here are consumer incomes, the level of food prices and non-economic (quality) factors such as health, safety etc. The supplyside, including the output of agriculture, the food industry and international trade, determines which foods are available and in what quantities and of what qualities. If a food is unavailable for whatever reason, consumers will be unable to consume it.

We will discuss the role of each of these factors in turn.

\section{Income levels}

The ability of consumers to purchase food in any economic system involving monetary exchange depends on their income level. This may be income from paid employment, returns on wealth or from transfer payments made by the government. A key measure used for the comparison of income levels in different countries and of standards of living, is gross national product (GNP) per capita (Table 1). The standard of living in Eastern European countries for 1988 was very low compared with that in many Western European countries and marginally less than in Mediterranean countries such as Spain 


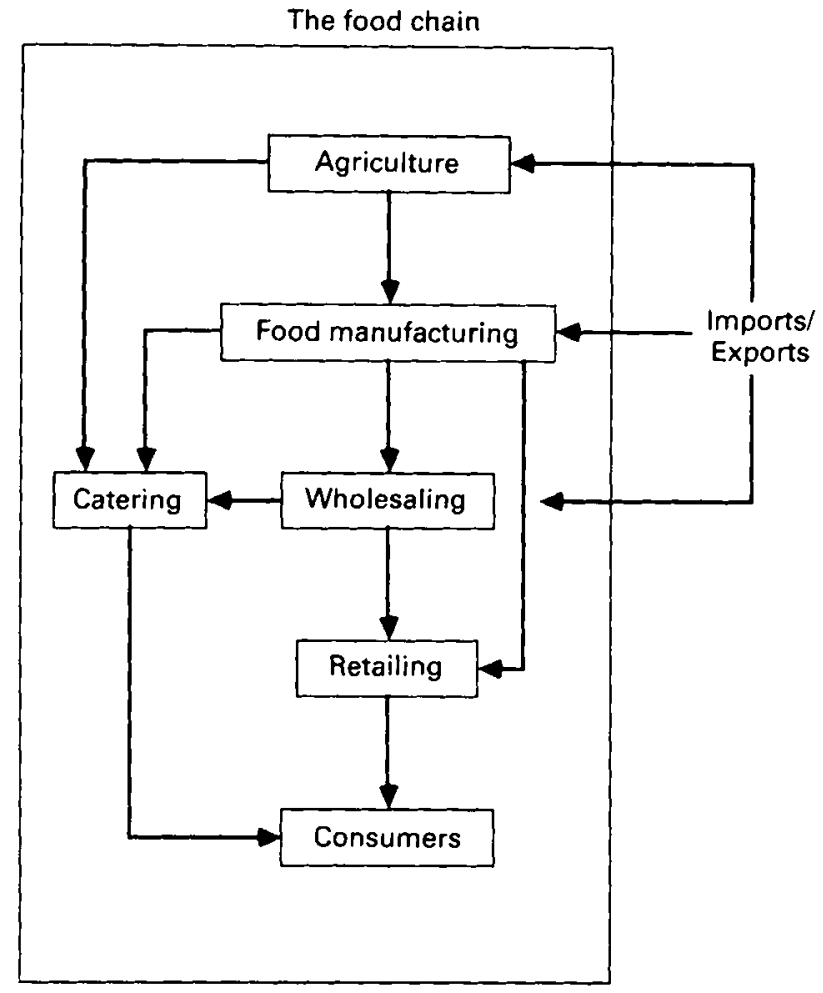

Fig. 1. The structure of the food chain.

Table 1. Gross national product (GNP) per capita for Eastern European and a selection of other countries, $1988 \dagger$

\begin{tabular}{lc}
\hline Country & GNP per capita \\
\hline Bulgaria & $*$ \\
Czechoslovakia & $*$ \\
GDR & $*$ \\
Hungary & 2460 \\
Poland & 1860 \\
Romania & $*$ \\
United Kingdom & 12810 \\
United States & 19840 \\
West Germany & 18480 \\
Greece & 4800 \\
Spain & 7740 \\
Portugal & 3650 \\
\hline
\end{tabular}

* Data not available.

$\dagger$ From World Development Report, 1990 (World Bank, 1990).

and Greece. This is significant for food choice given that in Eastern European countries, on average, up to $50 \%$ of income has been devoted to food compared with $13 \%$ in the UK during 1989. However, in the future we would expect this to fall as consumers have 
Table 2. Average annual growth rates in real incomes per capita, 1982-88 (\%)*

\begin{tabular}{lccccccc}
\hline Country & 1982 & 1983 & 1984 & 1985 & 1986 & 1987 & 1988 \\
\hline Bulgaria & 4.15 & 2.7 & 2.9 & 2.8 & 2.8 & 4.0 & 3.4 \\
Czechoslovakia & -1.1 & 1.9 & 1.4 & 0.6 & 2.5 & $3 \cdot 0$ & - \\
GDR & $4 \cdot 1$ & $2 \cdot 4$ & 5.1 & 5.2 & 5.7 & 4.5 & - \\
Hungary & 0.9 & 1.1 & 1.0 & 1.9 & 2.4 & 0.7 & - \\
Poland & -20.5 & 1.1 & -0.5 & 2.2 & 4.0 & -2.2 & - \\
Romania & - & - & - & - & - & - & - \\
\hline
\end{tabular}

* From Marks (1990)a).

Table 3. Average annual growth rates in total consumer expenditure at constant prices, $1982-87(\%) \dagger$

\begin{tabular}{lrrrrrr}
\hline Country & 1982 & 1983 & 1984 & 1985 & 1986 & 1987 \\
\hline Bulgaria & 3.7 & 2.9 & 4.9 & 3.3 & 3.6 & 6.9 \\
Czechoslovakia & -1.1 & 2.8 & 3.0 & 2.7 & 3.4 & 3.5 \\
GDR & 1.2 & - & 3.7 & 4.7 & 4.5 & 3.8 \\
Hungary & 1.4 & 0.6 & 0.9 & 1.2 & 2.0 & 3.1 \\
Poland & -11.5 & 5.8 & 4.4 & 2.9 & 4.8 & 2.9 \\
Romania & 3.7 & 3.8 & 3.6 & 2.8 & 2.2 & 3.2 \\
\hline
\end{tabular}

* Current prices.

$\dagger$ From Marks (1990a).

to increasingly enter the market for goods and services which were previously provided by the state, and as incomes begin to rise and Engel's law takes effect in the positive direction.

From these findings it would appear that income could potentially act as a major constraint on food choice within Eastern Europe. However, some of these countries have achicved significant growth in real incomes over recent years, notably Bulgaria and the GDR (Table 2). In other cases the growth rate achieved has been less successful and Poland has even experienced temporary reductions in real income over the period 1982-88. Related to growth in real income is growth in consumer expenditure. Given the significant proportion of total expenditure devoted to food, total expenditure can be regarded as a relatively good indicator of growth in food expenditure.

Over the period 1982-87 most of the Eastern European countries achieved relatively high rates of growth in consumer expenditure (Table 3 ). Typically, these exceeded rates of growth in real income as more goods become available for consumption and money is brought out of savings. However, in some cases the rate of growth in expenditure is less than growth in real incomes, for example, the GDR, where presumably a proportion of increased incomes was diverted into savings.

Although significant rates of growth in real incomes and consumer expenditure have been achieved in some Eastern European countries, income levels still remain low compared with Western European countries. The economic relationship between consumer food expenditure and level of income is given by the income elasticity of 
Table 4. Income elasticities for various commodities and services in Hungary, 1972*

\begin{tabular}{lcc}
\hline Commodity/Service & Urban households & Rural households \\
\hline Services & 1.42 & 1.18 \\
Consumer durables & 1.35 & 1.62 \\
Other industrial goods & 0.98 & 0.75 \\
Tea, coffee, tobacco, alcohol & 0.97 & 0.98 \\
Buildings & 0.88 & 0.93 \\
Clothing & 0.82 & 0.71 \\
Total food & 0.52 & 0.60 \\
Restaurant meals & 2.03 & 0.95 \\
Sweets & 0.99 & 0.74 \\
Dairy products & 0.87 & 0.77 \\
Butter & 0.79 & 0.67 \\
Fruit & 0.69 & 0.77 \\
Meat products & 0.66 & 0.70 \\
Vegetable oils & 0.65 & 0.01 \\
Vegetables & 0.56 & 0.64 \\
Meat & 0.51 & 0.89 \\
Eggs & 0.50 & 0.66 \\
Sugar & 0.32 & 0.56 \\
Poultry & 0.26 & 0.66 \\
Milk & 0.23 & 0.45 \\
Bread & 0.12 & 0.34 \\
Bacon & $0 \cdot 09$ & 0.48 \\
Potatoes & 0.07 & 0.32 \\
Lard & -0.08 & 0.44 \\
Flour and pasta & -0.10 & 0.36 \\
\hline \hline
\end{tabular}

* From Berger (1985).

demand. (This is calculated as: (\% change in expenditure) $/(\%$ change in income). A positive value indicates that an increase in income increases expenditure on a particular good. A negative value that an increase in income reduces expenditure on a particular good. The greater the absolute value of the elasticity, the more responsive its demand is to the level of income.) Estimates of this measure are not widely available for Eastern European countries; however, we do have some values for Hungary, although they are slightly dated (Table 4). Although these income elasticities may not be directly applicable to all Eastern European countries and are likely to have changed since 1972, we would hypothesize that the magnitude of any differences are likely to have been relatively limited.

These income elasticities indicated what is likely to happen as income rises in Eastern Europe and Hungary in particular. The income elasticity for food expenditure in total is 0.52 for urban households and $\mathbf{0 . 6 0}$ for rural households. Therefore, as incomes rise, food expenditure is likely to rise, although at a slower rate than incomes meaning that over time the proportion of income spent on food is likely to diminish. This has been the experience in Western Europe and follows the pattern predicted by Engel's Law (Fig. 2). As incomes rise, changes also occur in the pattern of food expenditure. For example, in urban households significant increases in expenditure on sweets, dairy products, butter, fruit etc. are expected. However, expenditure on flour and pasta and on lard is likely to 


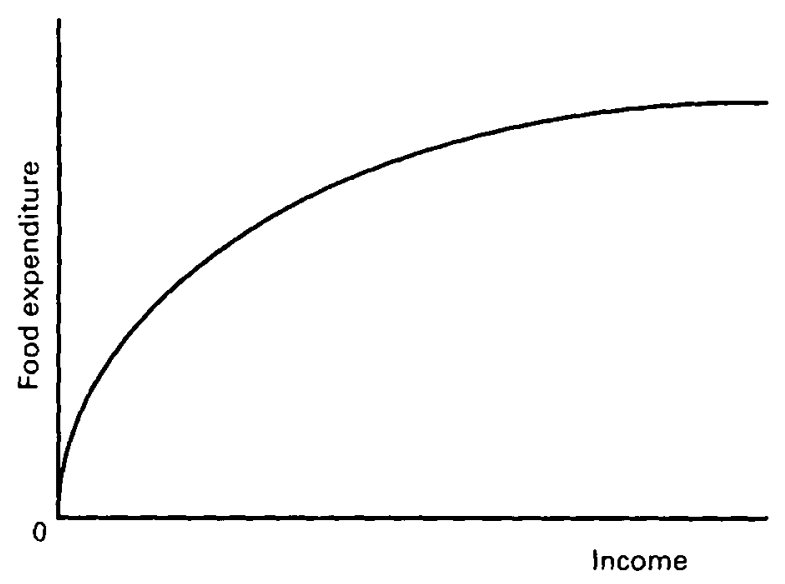

Fig. 2. The Engel curve for food expenditure with rising income.

fall and only small increases in expenditure on potatoes, bacon, bread, milk, poultry etc. are anticipated. Changes in the level of income have significant effects on food consumption patterns and, thus, on the nutritional status of the population.

At present, real incomes have fallen for many consumers within Eastern European countries as a short-term consequence of the process of economic reforms. In this situation the income elasticities work in the opposite direction. Reductions in food expenditure are anticipated, although less so than for other goods such as consumer durables, alcohol, tobacco and beverages. Over all, in the first half of 1990 , food consumption in Hungary is estimated to have fallen by $15 \%$ and in Poland by $30 \%$ (Csaki, 1990). Changes in the consumption of specific foods will have occurred. From the income elasticities, consumption of sweets, dairy products etc., is expected to fall and consumption of flour and pasta, and lard to have increased. The greater stability of food expenditure towards changes in the level of income is a desirable feature, although the income elasticity of demand for food in low-income groups is likely to be higher (for example, rural households) and, therefore, larger swings in food expenditure occur.

\section{Food prices}

Whilst price controls were in operation in Eastern Europe, the impact of low incomes on food choice is likely to have been restricted. Typically prices were maintained at very low levels which did not reflect true production costs. However, low income levels typically result in great price sensitivity. Some Eastern European countries, for example Poland, have experienced high rates of inflation, which will have affected food consumption (Table 5). Although in many cases price controls existed for food products, increases in prices for other goods may have reduced the amount of income available for food given the flexible nature of its contribution to total expenditure.

The relationship between food prices and the demand for food is given by the price elasticity of demand. (This is given by: (\% change in quantity demanded)/(\% change in price). This is always negative indicating that an increase in price results in a fall in 
Table 5. Consumer price indices for Eastern Europe, 1982-87*

\begin{tabular}{|c|c|c|c|c|c|c|}
\hline Country & 1982 & 1983 & 1984 & 1985 & 1986 & 1987 \\
\hline Bulgaria & $100 \cdot 7$ & $102 \cdot 1$ & $102 \cdot 8$ & 104.5 & $108 \cdot 2$ & $108 \cdot 3$ \\
\hline Czechoslovakia & $105 \cdot 9$ & 106.9 & 107.9 & $110 \cdot 4$ & $111 \cdot 0$ & $111 \cdot 1$ \\
\hline GDR & $100 \cdot 2$ & $100 \cdot 2$ & $100 \cdot 2$ & $100 \cdot 2$ & $100 \cdot 2$ & $100 \cdot 2$ \\
\hline Hungary & $111 \cdot 7$ & $120 \cdot 0$ & $129 \cdot 8$ & 138.8 & $146 \cdot 3$ & 158.7 \\
\hline Poland & 247.7 & $304 \cdot 7$ & $352 \cdot 8$ & 403.6 & 473.4 & $594 \cdot 1$ \\
\hline Romania & $119 \cdot 3$ & $125 \cdot 9$ & 127.0 & $127 \cdot 5$ & $127 \cdot 5$ & - \\
\hline
\end{tabular}

* From Marks (1990a).

demand. The greater the absolute value of the elasticity, the greater the responsiveness of demand to a change in price.) Estimates of price elasticities are very difficult to calculate for many Eastern European countries. Given the existence of price controls, data through which the impact of price changes on demand can be calculated are usually not available. However, we would expect consumers to be highly price sensitive for food products in general. It is also likely that the level of price sensitivity has increased since the imposition of economic reforms given the constraints that have been imposed on income levels. Given that over this period prices have risen significantly as a result of the removal of price controls, significant changes in food consumption patterns is expected.

In Eastern Europe the economic factors of incomes and food prices have been dominant determinants of food choice. Furthermore, their role has increased since the imposition of economic reforms as short-term economic problems have been experienced. However, there has also been a significant role of supply-side factors which have affected the availability of food products.

\section{Food availability}

The situation with regard to the availability of food products is very different between the countries of Eastern Europe both in terms of aggregate food supplies and specific products. Although it is difficult to obtain comparable data on specific products, information is available on availability of broad commodity groups (Table 6). It can be seen that there are significant differences in the supply of many basic agricultural commodities including fruit and vegetables, sugar, animal fats and meat.

In recent years agriculture within Eastern Europe has been relatively successful at meeting the demand for basic food products. The agricultural sectors in these countries were subject to a policy which aimed to increase self-sufficiency in basic agricultural commodities. In particular increased grain production was a major target (Table 7), although the success of this policy has been limited. Within meat production, poultry and pork were developed and beef production was relatively static. Egg production was rapidly expanded and milk production was moderately developed except in Hungary where it represented a major area of development (Table 8).

The agricultural sectors of the Eastern European countries are now subject to major economic restructuring. Traditionally this sector was subject to high levels of collectivization with state farms and collectives accounting for the vast majority of agricultural land with private use highly restricted (Table 9). The one exception was Poland which had 


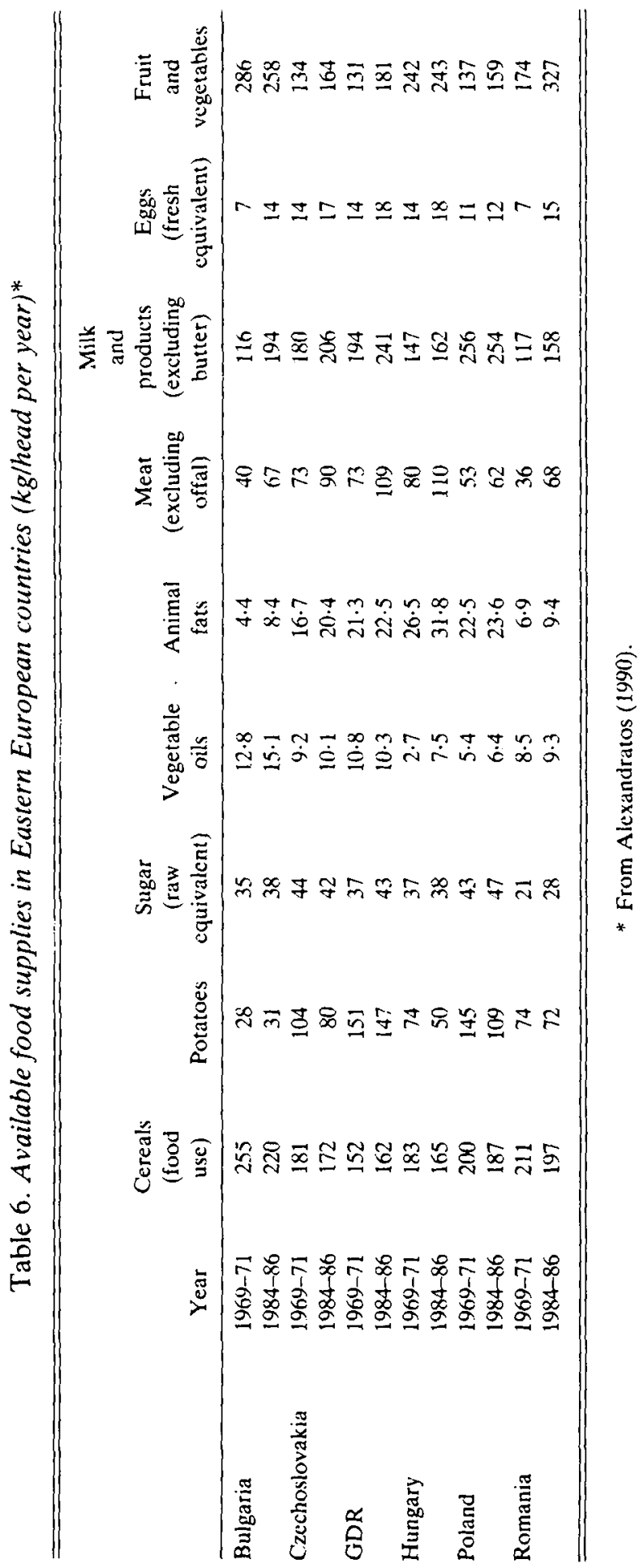


Table 7. Planting area of major crops $\left(\times 10^{3} \text { hectares }\right)^{*}$

\begin{tabular}{lcccccc}
\hline Commodity & Bulgaria & Czechoslovakia & GDR & Hungary & Poland & Romania \\
\hline Wheat & 1138 & 1239 & 777 & 1242 & 2195 & 2600 \\
Maize & 563 & 190 & - & 1124 & 51 & 3100 \\
Barley & 360 & 751 & 895 & 282 & 1175 & 680 \\
Potatoes & 40 & 170 & 431 & 74 & 1858 & 325 \\
Sunflower seed & 240 & 27 & - & 359 & - & 460 \\
\hline
\end{tabular}

* From Csaki (1990).

Table 8. Production of livestock products in 1989 compared with 1970 (\%)*

\begin{tabular}{lcccccc}
\hline Commodity & Bulgaria & Czechoslovakia & GDR & Hungary & Poland & Romania \\
\hline Total meat & 206 & 157 & 156 & 170 & 141 & 181 \\
Beef and veal & 155 & 130 & 122 & 101 & 130 & 109 \\
Pig meat & 281 & 166 & 168 & 177 & 136 & 197 \\
Cow milk & 170 & 148 & 131 & 167 & 105 & 158 \\
\hline
\end{tabular}

* From Csaki (1990).

Table 9. Organization of Eastern European agriculture, $1988 \dagger$

(Values are expressed as \%)

\begin{tabular}{lccc} 
Country & State farms & Cooperative farms & Private use \\
Bulgaria & $89.9^{*}$ & - & $10 \cdot 1$ \\
Czechoslovakia & 30.3 & 63.6 & $6 \cdot 1$ \\
GDR & 7.7 & 82.5 & 9.8 \\
Hungary & 14.9 & 70.9 & 14.2 \\
Poland & 18.5 & 3.6 & 77.9 \\
Romania & $90.5^{*}$ & - & 9.5 \\
\hline
\end{tabular}

* State and cooperative farms.

+ From Csaki (1990).

$77.9 \%$ of land down to private use in 1988 (Csaki, 1990). The governments of Eastern Europe have committed themselves to a policy of decollectivization and privatization of agricultural holdings. Undoubtedly this represents a major change in the ownership and organizational structure of agriculture in Eastern Europe which will affect the productivity of farm units, although some reforms had already been initiated under the old regimens. Adjustments in productivity may not necessarily be in a positive direction, particularly in the short term.

The reforms in agricultural production are occurring simultaneously with reforms of agricultural policy which are leading the movement towards the creation of true markets for agricultural commodities. In the short term these changes could lead to severe supply problems in Eastern Europe.

Food manufacturing remains relatively unimportant within Eastern Europe in comparison with the UK, and much of the rest of Western Europe, although its role has 
Table 10. Growth in output of selected food industries, $1980-87(\%)^{*}$

\begin{tabular}{lcccccc}
\hline \hline Commodity & Bulgaria & Czechoslovakia & GDR & Hungary & Poland & Romania \\
\hline Canned fish & 71 & 25 & 14 & -- & 20 & 18 \\
Meat & 99 & 67 & 67 & 118 & 62 & - \\
Canned meat & 150 & 41 & 54 & 196 & 35 & - \\
Canned fruit & 12 & 10 & 83 & 113 & 47 & 54 \\
Butter & 85 & 71 & 44 & 65 & 106 & 23 \\
Sugar & 12 & 2 & 66 & 60 & 20 & 71 \\
$\quad$ Vegetable oils & 7 & 78 & 20 & 459 & 54 & - \\
$\quad$
\end{tabular}

* From Marks (1990b).

steadily increased over recent years. Significant increases in output have been achieved for a number of food products, although the success of the sector differs between the countries and productivity still remains low by Western standards (Table 10). Growth in productivity in food manufacturing is likely to be a problem for the foreseeable future, with the ability to import new production technology highly limited. However, the role of investment by Western food companies could be valuable, although as yet this remains an unknown entity.

The problems of the food processing sector in Eastern Europe are exacerbated by inadequacies within the transport and storage system along the chain. Wastage represents a significant proportion of total output, particularly for fresh produce such as fruit and vegetables where although self-sufficiency is about $90-100 \%$, supplies are far from adequate and quality is low. Developments within food manufacturing will be wasted if the efficiency of the remainder of the food chain is not improved.

The food manufacturing sectors in these countries are now undergoing severe economic restructuring with the removal of subsidies and the movement to market prices which more accurately reflect the true costs of production. Given the monopoly status of many of these processors and their relatively inefficient methods of production, significant increases in prices are occurring. Although supply from these sectors may not be lacking in a quantitative sense, there are significant qualitative supply problems in terms of the variety and quality of food products available. Examples are fatty meat and poor fruits and vegetables. This suggests that given the choice, consumers may not elect to buy the produce available (Gardner, 1990). It is actually very difficult to obtain data on the supply of food products in many Eastern European countries and it has been suggested that official figures should be cut by between 20 and $30 \%$, according to the country involved, to obtain realistic estimates. A number of calculations have been made of increases in the supply of food products required for Eastern Europe as a whole to attain food consumption patterns on a par with those in the West. One example of these produced the following estimates: beef $30 \%$, pig meat $30-40 \%$, poultry meat $40 \%$, milk supplies $20-25 \%$. These changes will require major investment and improved productivity in agriculture, food-processing facilities and the transport and storage system over the next few years.

Inadequacies within agriculture and the food-processing sector in Eastern Europe have led to reliance on imports as a source of supply in many countries. Over all, Poland, Czechoslovakia, and the former GDR were net importers in 1988 whereas Hungary, 
Table 11. Net trade balances on aggregate for agricultural products*

\begin{tabular}{lrrr} 
Country & Imports & Exports & Balance \\
Bulgaria & 1196 & 2236 & +1040 \\
Czechoslovakia & 13617 & 7427 & -6190 \\
GDR & 11351 & 6114 & -5237 \\
Hungary & 71317 & 106684 & +35367 \\
Poland & 350821 & 165063 & -185758 \\
Romania & 10773 & 4838 & +9840 \\
\hline
\end{tabular}

* From Marks (1990b).

Table 12. Estimated net trade balances by quantity for food commodities, $1988^{* \dagger}$

\begin{tabular}{|c|c|c|c|c|c|c|}
\hline Commodity & Bulgaria & Czechoslovakia & GDR & Hungary & Poland & Romania \\
\hline Cereals & -891 & -570 & -2158 & 1873 & -3106 & 332 \\
\hline Potatoes & -94 & -31 & -18 & 7 & 644 & -31 \\
\hline Sugar & -370 & -38 & -138 & 79 & 25 & -149 \\
\hline \multicolumn{7}{|l|}{ Live animals: } \\
\hline Cattle & $26 \cdot 8$ & $31 \cdot 2$ & 90 & 134.7 & $562 \cdot 4$ & 30 \\
\hline Sheep & $1293 \cdot 4$ & 9 & 350 & 1367.9 & $905 \cdot 5$ & 350 \\
\hline Pigs & & -54 & 700 & 465 & $-229 \cdot 3$ & $-46 \cdot 5$ \\
\hline \multicolumn{7}{|l|}{ Meat: } \\
\hline Beef & -7.8 & $42 \cdot 7$ & 11 & $20 \cdot 4$ & $3 \cdot 4$ & -208.9 \\
\hline Sheep meat & 11.8 & 0.1 & -1 & $1 \cdot 8$ & - & -40 \\
\hline Pig meat & 1.7 & $3 \cdot 5$ & 22 & 133.7 & 0.1 & $-134 \cdot 3$ \\
\hline Poultry meat & $35 \cdot 3$ & 13 & -2 & $236 \cdot 2$ & $16 \cdot 7$ & $-178 \cdot 6$ \\
\hline Edible offals & 3.9 & $-14 \cdot 6$ & $-4 \cdot 4$ & $1 \cdot 2$ & $1 \cdot 6$ & $0 \cdot 1$ \\
\hline Canned meat & 57.5 & -3.9 & -2 & 64 & $49 \cdot 2$ & $-134 \cdot 2$ \\
\hline Sausages & $-0 \cdot 3$ & $-5 \cdot 3$ & -0.5 & $12 \cdot 5$ & $1 \cdot 3$ & $-8 \cdot 6$ \\
\hline Lard & 13 & -2 & 15 & 41 & - & -86 \\
\hline \multicolumn{7}{|l|}{ Dairy products: } \\
\hline Butter & $-4 \cdot 2$ & 14 & $25 \cdot 8$ & -2 & $-34 \cdot 1$ & $-427 \cdot 6$ \\
\hline Cheese & $23 \cdot 4$ & 7.9 & $-3 \cdot 5$ & $9 \cdot 6$ & $-9 \cdot 3$ & $-6 \cdot 6$ \\
\hline Whey & -6 & -0.9 & - & -0.3 & - & - \\
\hline \multicolumn{7}{|c|}{ Milk and cream: } \\
\hline Dry & $-4 \cdot 2$ & $64 \cdot 5$ & $0 \cdot 8$ & 0.5 & $38 \cdot 2$ & $-57 \cdot 7$ \\
\hline Condensed & $-0 \cdot 1$ & 13.5 & - & $-1 \cdot 6$ & - & $25 \cdot 4$ \\
\hline Dried eggs & 1 & -- & 0.3 & 0.5 & - & - \\
\hline Eggs in shell & $7 \cdot 6$ & $6 \cdot 3$ & $16 \cdot 8$ & $6 \cdot 5$ & $2 \cdot 6$ & -9.4 \\
\hline
\end{tabular}

* Negative values indicate net imports, positive values net exports.

+ From Marks (1990h).

Bulgaria and Romania were net exporters (Table 11). However, these figures obscure the reliance on imports of specific food products faced by all Eastern European countries especially by value (Table 12). For example, Hungary imported a substantial quantity of food equal to $68 \%$ of its exports by value and was a net importer of butter, whey and condensed milk and cream. The prolonged reliance on food imports is a major problem for Eastern European countries. Traditionally they have been major traders with the 
Table 13. Food shipments to the former $G D R\left(\times 10^{3} D M\right) \dagger$

\begin{tabular}{lc}
\hline Food product & $\begin{array}{c}\text { Change } 1989 \text { compared } \\
\text { with } 1990(\%)^{*}\end{array}$ \\
\hline Plant products & $813 \cdot 1$ \\
Fresh fruit & $14607 \cdot 0$ \\
Fresh vegetables & $66997 \cdot 4$ \\
White wine & $342 \cdot 2$ \\
Live animals and animal products & $207 \cdot 5$ \\
Fish products & $127 \cdot 3$ \\
Bakery products & $855 \cdot 5$ \\
Processed fruit and vegetables & $529 \cdot 9$ \\
Fruit juices, cola, water & $1527 \cdot 9$ \\
Sweets & $248 \cdot 8$ \\
Milk, butter, cheese & $616 \cdot 9$ \\
Meat and meat products & $332 \cdot 2$ \\
Coffee, tea & $400 \cdot 2$ \\
Beer & $10158 \cdot 6$ \\
Spirits & $190 \cdot 0$ \\
\hline
\end{tabular}

Soviet Union, but since 1989 have increasingly turned to alternative sources of supply. These imports represent a major drain on hard currency reserves, a requirement which even the Soviet Union is enforcing in its exports to Eastern Europe.

These trade figures represent only basic agricultural commodities, they do not indicate the trade in processed products. As trade across Eastern European borders has become increasingly free, there has been a steady flow of food products from Western Europe. Eastern European consumers appear to have a great appetite for these foods at present as is illustrated by the flow of food products into the former GDR from the former Federal Republic from January to May 1990 compared with the same period in 1989 (Table 13). For all the products described, shipments have at least doubled in the space of 1 year. It is likely that, given the problems in Eastern European food-processing capacity, this trade will increase in the foreseeable future creating an increasing foreign exchange problem and a steady increase in the consumption of 'Western' food products. However, in the short term imports of food products are likely to be constrained through economic factors and an aggregate fall in imports of $15 \%$ by volume has been forecast for 1990-92 (Agra Europe, 1990). This will be despite anticipated reductions in output within the agricultural sector in particular.

\section{Non-economic factors}

Non-economic factors including health and food safety concerns are important determinants within food choice in the UK. We will say very little about these factors in the context of Eastern Europe. This is not because we believe they are unimportant but because we believe, at least in the short term, that economic factors will be the major influence on East European diets. A survey for The Flora Project (1990) showed a great difference in attitudes towards healthy eating within Eastern Europe. In Czechoslovakia, $44 \%$ of respondents declared a healthy diet to be a major concern, whereas in Hungary 
the response was only $14 \%$; this response compares with that of $44 \%$ in the UK. In Czechoslovakia at least, healthy eating would appear important in food choice, although what consumers mean by this term may not be fully understood. In the same survey air pollution, water pollution and food safety were declared to be major concerns within Eastern Europe.

Our hypothesis about the role of economic factors is borne out by The Flora Project (1990) survey. In both Hungary and Czechoslovakia, $60 \%$ of respondents were concerned about the cost of food and availability of 'healthy' food items. Fruit and vegetables were a particular concern, especially in winter. Concerns over the quality of foods and the diet are highly income elastic. That is as incomes rise, consumers become increasingly concerned with non-economic factors as the constraints imposed by economic factors recedes. We can, therefore, expect, as in the UK for example, health and nutrition to become an increasingly important issue in the longer term, although its role in the short run is likely to remain limited.

\section{FOOD CONSUMPTION PATTERNS IN THE FUTURE}

If in the past, food consumption was determined largely by availability, in the future, at least the medium- to long-term availability will cease to be the major constraint; all that can be afforded will be available on the international market, if not produced domestically. Consumption will, thus, be determined by each consumer choosing that particular combination of foods that provides the greatest pleasure, given his or her income and the prices faced, as described previously.

An interesting question is whether, with the same incomes and facing the same prices, consumers in all countries would consume more or less the same things in the long term or whether cultural/attitudinal differences would mean that difference in diet would persist, i.e. is culture immune to the sorts of social integration processes ongoing in Western Europe? This is a continuing and unsettled debate in the West, where it appears that the Southern countries are adopting the consumption patterns of the North at the same time that the Northern ones are being urged to adopt the Mediterranean diet (and generally responding). But how far will the process of convergence go? What seems probable is that groups of consumers with similar attitudes and eating habits will develop, with group 'membership' determined not by country of origin but by other social/economic/demographic and psychological variables. As the market researchers Nielsen observe, consumers in the metropolitan areas of London, Paris, Madrid and Brussels may have more in common with one another than they do with other consumers in their own country (The Grocer, 1990).

However, all this must seem a long way off to the relatively poor Eastern European countries. What seems most likely for them is that they will gradually adopt eating habits in line with those of culturally and economically similar countries. If their economies are too much exposed to external competition too quickly, the change may be considerably faster than gradual. The former East Germany is of course a special case in terms of the rate and nature of its adjustment process.

Table 14 gives data generated from the database, Food and Health Indicators in Europe (World Health Organization, 1990). The data are from food balance sheets, with all the limitations that imposes, for 1987. They are the best data available to us for cross-country comparisons. 


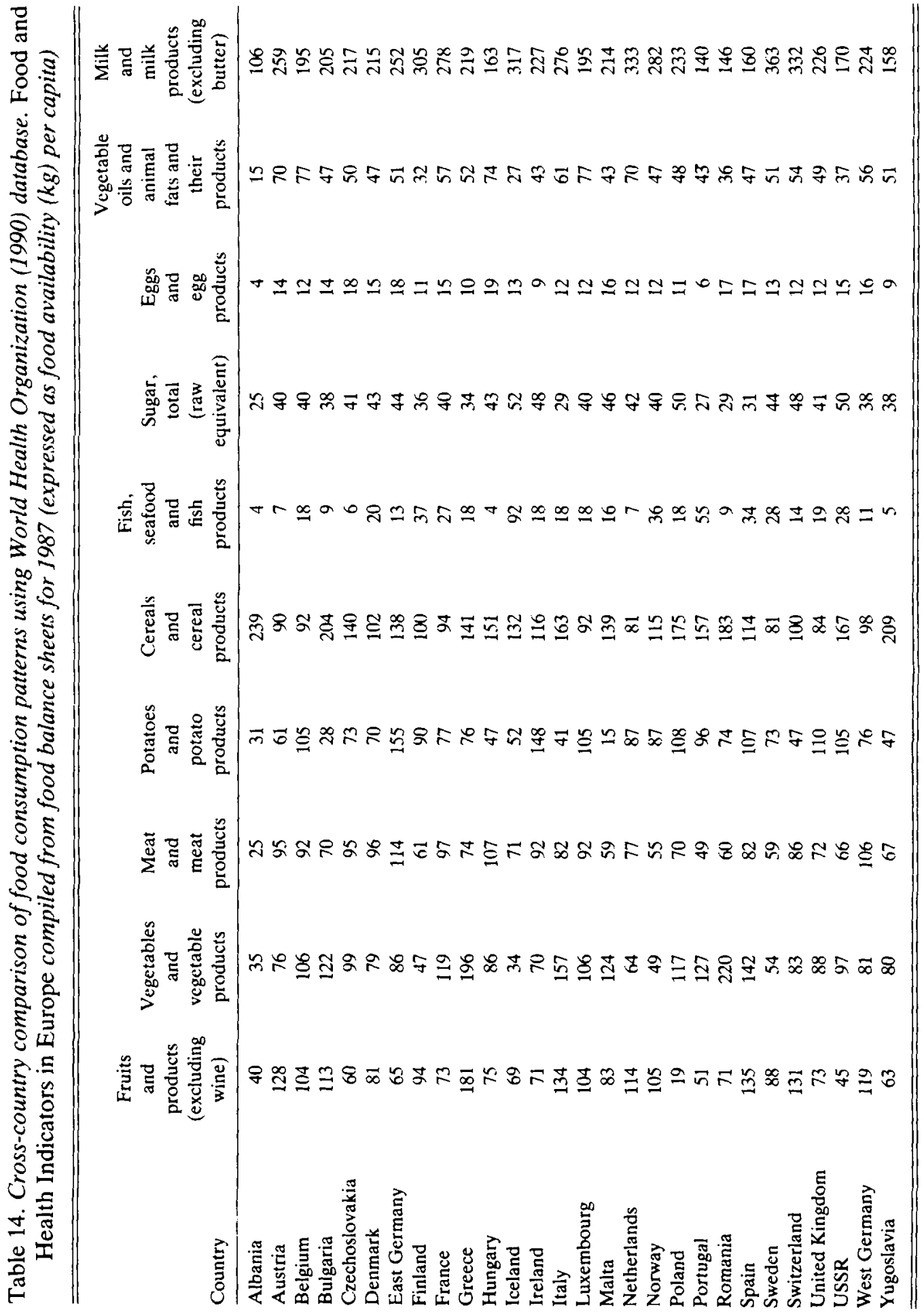


Perhaps the most dramatic change in East European consumption patterns can be expected in the meat sector. Table 14 shows meat consumption in the former East Germany and in Hungary to be the highest in Europe, a position in no way compatible with their income levels. Czechoslovakia is not far behind, while Poland, Bulgaria and Romania have higher levels than would be expected. This has come about through the massive subsidization of pig and poultry production under the previous regimes, a situation that cannot continue. It would not be surprising to see meat consumption fall to below $50 \mathrm{~kg} / \mathrm{head}$ in some of these countries. Perhaps fish consumption, which is rather low, will partially replace the reduced meat.

Consumption of cereal and cereal products is unexpectedly high with Bulgaria, Romania and Poland all showing levels above any in Western Europe, while the others group uneasily with the Mediterranean countries. Some reduction in consumption may be anticipated if incomes start to rise, as these products have negative income elasticities. The same may be said for potato consumption in East Germany and Poland.

Romania and Bulgaria, showing clear signs of a Mediterranean diet, have high levels of vegetable and, to a lesser extent, fruit consumption. Some of the other Eastern European countries have low consumption levels of these products, particularly fruit. Again this is largely a function of past availability, but, given the perishability of these products, increased consumption is to a large extent dependent on improvements in the food production and distribution systems to make more produce available at prices consumers can afford. Science and technology do of course make it increasingly possible to extend shelf-lives (through controlled/modified atmosphere, packing and even irradiation) so trade may expand; but one would anticipate this to be mainly at the higher value end of the product range and so appeal to the more affluent members of these societies.

For sugar, Bulgaria and Romania again group with the Mediterranean countries, while the other four are in line with Northern European consumption patterns. A slow convergence can be expected, in line with that taking place in Western Europe. Consumption of eggs and to a lesser extent milk are, like meat, higher than would be expected given income levels; something nearer the Portuguese level would appear likely. Consumption of fats and oils shows little overall pattern, although generally consumption is slightly higher than in other countries with similar income levels and, therefore, may be expected to fall somewhat.

Of course we are always told by nutritionists that there is no such thing as an unhealthy food, only an unhealthy diet. We, therefore, leave it to nutritionists to interpret whether the changes in consumption patterns that we predict will result in healthier diets in these countries. As non-specialists it would seem to us that the implied reductions in the share of meat and dairy products in the diet are in line with current recommendations in the West. Poverty is probably good for you, as long as you do not have too much of it!

The changes referred to are of a medium-term nature. They make little mention of the short-term, largely unpredictable, impact of the adjustment period during which high levels of unemployment are already being experienced (with obvious impact on food consumption for those affected), availability remains a constraint (partly because of shortage of foreign exchange, partly because of still underdeveloped markets) or, in the opposite direction, consumers are perhaps over-reacting to the appearance in shops of Western goods which have previously been denied them.

A host of other factors will impinge on the simple changes we have discussed. As 
incomes rise the demand for processed convenience food products and for meals taken outside the home will rise sharply, as in the West. Greater variety will be demanded and new products from Western food manufacturers and from 'exotic' origins (bananas, citrus, tropical beverages) will appear on supermarket shelves to meet the demand. Foreign travel will promote, as it has in the West, an acquisition of some of the eating habits and recipes of the countries visited (unless the country happens to be the UK).

There are also great imponderables concerning the magnitude and impact of changes in agricultural policies in Europe and elsewhere brought about by reform of the CAP, GATT negotiations etc. A more liberal trading system should mean two things for the East: less surplus production from the West and, therefore, higher world prices, which will feed through to higher prices to be paid by East European consumers: and higher prices received for exports from the East combined with easier access to Western markets. This should feed through to greater prosperity in the East (whose countries are predicted by the OECD to become net exporters of agricultural produce) and more income to be spent on food. It will be spent on products with high income elasticities like meat and dairy products, thus counteracting the beneficial nutritional effects of the other changes we have discussed.

\section{CONCLUSIONS}

In the coming years the East European countries face the major challenge of restructuring their economies to adapt to the competition associated with open capitalist economies. Much of the stress associated with this adjustment will be felt in the production sector, but in the present paper we have focused on the demand side, attempting to explain how food consumption decisions are made in a capitalist economy and what are the likely implications of a change in system for diets in the East European countries. In so doing, we hope we have assisted nutritionists to understand and assess the nutritional implications of the change.

\section{REFERENCES}

Agra Europe (1990). Agra Europe July 20, 1991. Tunbridge Wells: Agra Europe.

Alexandratos, N. (1990). European Agriculture: Policy Issues and Options to 2000. Rome: FAO.

Berger, A. (1985). Food Economics. Budapest: Akademiai Kiado.

Csaki, C. (1990). Agricultural changes in Eastern Europe at the beginning of the 1990s. American Journal of Agricultural Economics 72, 1233-1242.

Eurofood (1990). East Germany: a hunger for Western goods. Eurofood December, 10.

Flora Project (1990). Attitudes of the Czechoslovakian, Hungarian and British Population to Diet and Health. London: Flora Project for Coronary Heart Disease.

Gardner, B. (1990). The challenges and the problems for East Europe's food industry. Eurofood May, 12-13.

Marks, H. F. (1990a). Food and Agriculture in Eastern Europe and the USSR: Facts and Figures. London: Elaine Warrell Assuciates.

Marks, H. F. (1990b). The food industry and foreign trade in Eastern Europe and the USSR. British Food Journal 92, 3-8.

The Grocer (1990). Report pinpoints emergence of new Euroconsumer. The Grocer, October 27.

World Health Organization (1990). Food and Health Indicators in Europe. Copenhagen: WHO Regional Office for Europe.

World Bank (1990). The World Development Report, 1990. Oxford: Oxford University Press. 